\title{
Radiant heat from propane jet fires
}

\author{
Mercedes Gómez-Mares*, Miguel Muñoz, Joaquim Casal \\ Centre for Technological Risk Studies (CERTEC), Department of Chemical Engineering, Universitat Politècnica de Catalunya, Diagonal 647, 08028 Barcelona, Catalonia, Spain
}

\section{A R T I C L E I N F O}

Article history:

Received 15 October 2009

Accepted 20 October 2009

\section{Keywords:}

Jet fire

Propane flames

Radiant heat intensity

Fraction of heat irradiated

Emissive power

\begin{abstract}
A B S T R A C T
Sonic propane jet fire experiments were carried out in absence of wind, with visible flame length ranging between 2.2 and $8.1 \mathrm{~m}$. The thermal radiation intensity increased with the mass flow rate and the flame length. The net heat released was also computed and a correlation for the flame length as a function of $Q$ is proposed. The surface emissive power and the fraction of heat irradiated were estimated by applying the solid flame model, assuming the flame to be a cylinder. The variation of the emissive power as a function of flame length was found to follow a linear equation. The fraction of heat irradiated $\eta$ was obtained from the value of the total radiative power; its average value for sonic propane gas flames was 0.07 .
\end{abstract}

(C) 2009 Elsevier Inc. All rights reserved.

\section{Introduction}

According to a recent study, one of each two recorded accidents involving a jet fire causes a domino effect [1]. The fuel most frequently involved in these cases was LPG. This information points out the importance of jet fires research in order to characterize the flame behaviour and prevent this type of accidents.

The purpose of this study is the analysis of the heat released by a relatively large scale propane jet fire affecting certain targets. Although several authors have studied this type of fire, most of them have analysed subsonic or small scale flames, or flares [2-8]. However, for most gases sonic velocity is reached if the pressure at the source is greater than 1.9 bar abs.; therefore, accidental jet fires are often sonic. Thus, this study is devoted to sonic propane jet fires.

Experimental tests were carried out and the thermal radiation intensity emitted from the flames was analysed as a function of flame length and fuel mass flow rate. The surface emissive power, the total radiant heat and the radiative fraction were also estimated and analysed. Finally, expressions are proposed to allow the prediction of flame length and emissive power.

\section{Experimental set-up}

The experimental facility was built at the Can Padró Safety Training Centre, located near Barcelona, Spain. A schema of the experimental set-up is shown in Fig. 1. The facility included a set of pipes which allowed obtaining vertical and horizontal jet fires, although in this paper only vertical jet fires are analysed.

\footnotetext{
* Corresponding author. Tel.: +34 934016675; fax: +34 934017150

E-mail address: m.gomez.mares@upc.edu (M. Gómez-Mares).
}

The gas pipe exit had a removable cap which allowed selecting different exit diameters; six orifice diameters were used: 10, 12.75, $15,20,25.5$, and $30 \mathrm{~mm}$. The fuel (commercial propane) was contained in a pressurized tank $\left(4 \mathrm{~m}^{3}\right)$. The liquid propane was vaporized while flowing through the pipe.

The propane pressure was measured at a point located $5 \mathrm{~cm}$ upstream the release point, using an electronic pressure transmitter. This was taken as the upstream stagnation pressure of the flow and allowed the calculation of the mass flow rate $m$.

Jet flame geometric parameters were studied by analyzing the images filmed by an AGEMA 570 Infrared Thermographic Camera (IR), located orthogonally to the flame. The recorded sequences could be decomposed frame by frame allowing the observation of the flame behaviour at each instant. This camera has a focal plane array detector of $320 \times 240$ pixels which is sensible to the radiation in a certain wave length. The spectral range for this one is $7.5-13 \mu \mathrm{m}$. The field of vision is $24^{\circ} \times 18^{\circ}$.

Three heat flow sensors (Schmidt-Boelter type) were located at different distances from the flame axis. These positions were varied during the experiments $(3,5$ and $10 \mathrm{~m})$.

A meteorological station (GroWeather) was used to measure continuously the ambient temperature, the relative humidity and the wind direction and velocity. These variables are important because they affect either the jet flame or the measurement instruments in a direct or indirect way.

A Field Point module was used as a data acquisition system. It consisted of a communication module FP-1001 (RS-485), three connection terminals FP-TB-1 and three input/output modules. Two laptops were used to collect the data from the different sensors. They recorded the measurement and controlled the devices operation. The IR camera, the meteorological station and the Field 


\section{Nomenclature}

$\begin{array}{ll}A_{F} & \text { flame cylinder area }\left(\mathrm{m}^{2}\right) \\ a & \text { constant in Eq. (8) }\left(\mathrm{K} \mathrm{MW}^{-1} \mathrm{~m}^{-1}\right) \\ a^{\prime} & \text { constant in Eq. (4) }\left(\mathrm{m} \mathrm{MW}^{-1}\right) \\ b & \text { constant in Eq. (8) (-) } \\ b^{\prime} & \text { constant in Eq. (4) (-) } \\ d & \text { exit diameter (m) } \\ E & \text { surface emissive power }\left(\mathrm{kW} \mathrm{m}^{-2}\right) \\ F & \text { view factor (-) } \\ I & \text { thermal radiation intensity }\left(\mathrm{kW} \mathrm{m}^{-2}\right) \\ L & \text { flame length (without lift-off) }(\mathrm{m})\end{array}$

$\begin{array}{ll}m & \text { mass flow rate }\left(\mathrm{kg} \mathrm{s}^{-1}\right) \\ P & \text { total radiative power }(\mathrm{kW}) \\ Q & \text { net heat released }(\mathrm{MW} \text { or } \mathrm{kW}) \\ T & \text { flame temperature }(\mathrm{K}) \\ x & \text { radial distance to the flame surface }(\mathrm{m}) \\ \Delta H & \text { combustion heat }\left(\mathrm{kJ} \mathrm{kg}^{-1}\right) \\ \varepsilon & \text { flame emissivity }(-) \\ \eta & \text { fraction of heat irradiated }(-) \\ \sigma & \text { Stefan-Boltzmann constant }\left(\mathrm{W} \mathrm{m} \mathrm{m}^{-2} \mathrm{~K}^{-4}\right) \\ \tau & \text { atmospheric transmissivity }(-)\end{array}$

Point were connected to them. Furthermore, the two laptops were connected through a network in order to synchronize the data acquisition.

The computers used FireAll [9]. This software was created at CERTEC to manage the operation of each one of the devices, allowing starting the recording of all the instruments at the same time. It simplifies the data analysis by generating separated files for each test, thus assuring a perfect synchronization of all the measurements.

\section{Test conditions}

Twenty tests were carried out, of which only the momentum dominated sonic commercial propane gas flames were chosen and analysed. The procedure started with the opening of a valve which made possible the flow of propane through the pipeline. The propane was vaporized as it flowed through the pipe up to the outlet. Downstream the gas outlet, the gas jet was ignited by means of an ignition source. The duration of each test varied as a function of the time required by the flame to reach the steady state, and of the number of mass flow rates tested in each experiment, ranging between 1 and $5 \mathrm{~min}$. The mass flow rate was computed from the temperature and pressure measurements made at the nozzle exit. The flame length was determined from the IR images (the flame was blue or almost transparent, and thus a video camera could not be used).

The propane mass flow rate ranged between 0.06 and $0.43 \mathrm{~kg} / \mathrm{s}$, and the visible flame length - lift-off not included - from 2.2 to $8.1 \mathrm{~m}$. The nozzle exit Reynolds number ranged between $8 \times 10^{5}$ and $3 \times 10^{6}$, which means that all the flames were on the turbulent regime. The Froude number was always greater than $2.4 \times 10^{5}$.

The ambient temperature ranged between $28^{\circ} \mathrm{C}$ and $32^{\circ} \mathrm{C}$, and the relative humidity between $45 \%$ and $53 \%$. The tests were carried out in still air.

\section{Influence of flow composition}

Only the tests in which the flame was fed by a gas flow were considered for the study, as the features of flames fed by gas or by a gas-liquid mixture are significantly different. The flames fed by gas are almost transparent, while the flames fed by a two-phase flow mixture are yellow and very luminous, as well as larger, as can be observed in Fig. 2 . The variation of flame length when the flow changed from gas to gas-liquid mixture during one of the test can be seen in Fig. 3.

It can be observed that when the gas-liquid mixture starts, the flame height increases significantly, growing from 3.5-6 $\mathrm{m}$ to 5$8 \mathrm{~m}$. This must be attributed to the increase in the fuel mass flow rate because of the presence of liquid droplets.

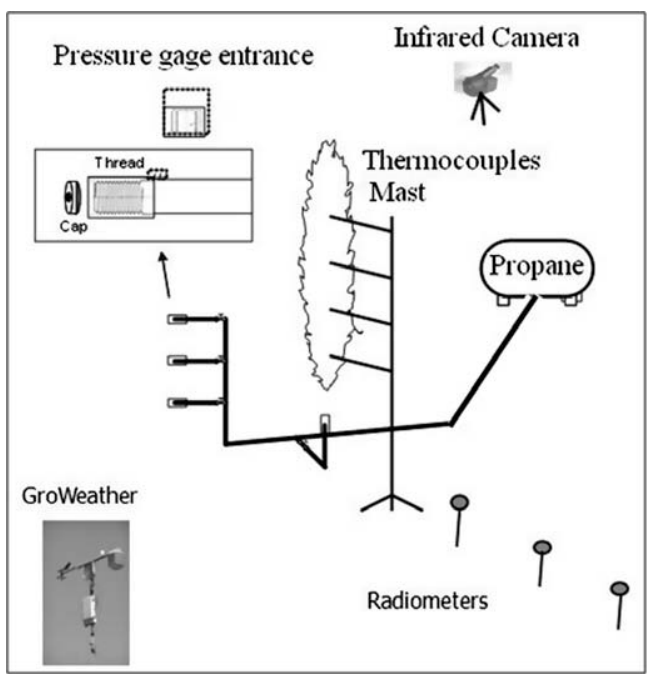

Fig. 1. Experimental set-up.

Furthermore, the radiant heat emitted from the flame increases also significantly when there is two-phase flow (Fig. 4). This is due to the fact that the combustion is less efficient and more soot is produced, as can be clearly observed in Fig. 2, while there is a much better combustion in the case of the fed gas flames. When there is two-phase flow, some of the energy is devoted to the evaporation of the liquid and the mixture with oxygen is more difficult and poorer, thus leading to low quality combustion.

This clearly indicates the importance of distinguishing between flames from a gas fuel and those from two-phase flow when predicting their thermal effects.

\section{Thermal radiation intensity}

According to the solid flame model, the thermal radiation intensity $I$ reaching a given target can be related to the flame emissive power by the following expression:

$I=F E \tau$

where $F$ is the view factor between the flame and the target, $E$ is the average surface emissive power and $\tau$ is the atmospheric transmissivity.

I can be measured directly by a radiometer, while $F$ and $\tau$ can be estimated using the equations found in the literature [10]. The estimated experimental uncertainty when measuring the thermal radiation intensity in this way is $\pm 3 \%$ with $95 \%$ of confidence level.

To calculate $F$, the radiation is assumed to be emitted by a cylinder which starts at the lift-off height (bottom of the flame) and finishes at the top of the flame. Then, if $I$ has been measured, from 


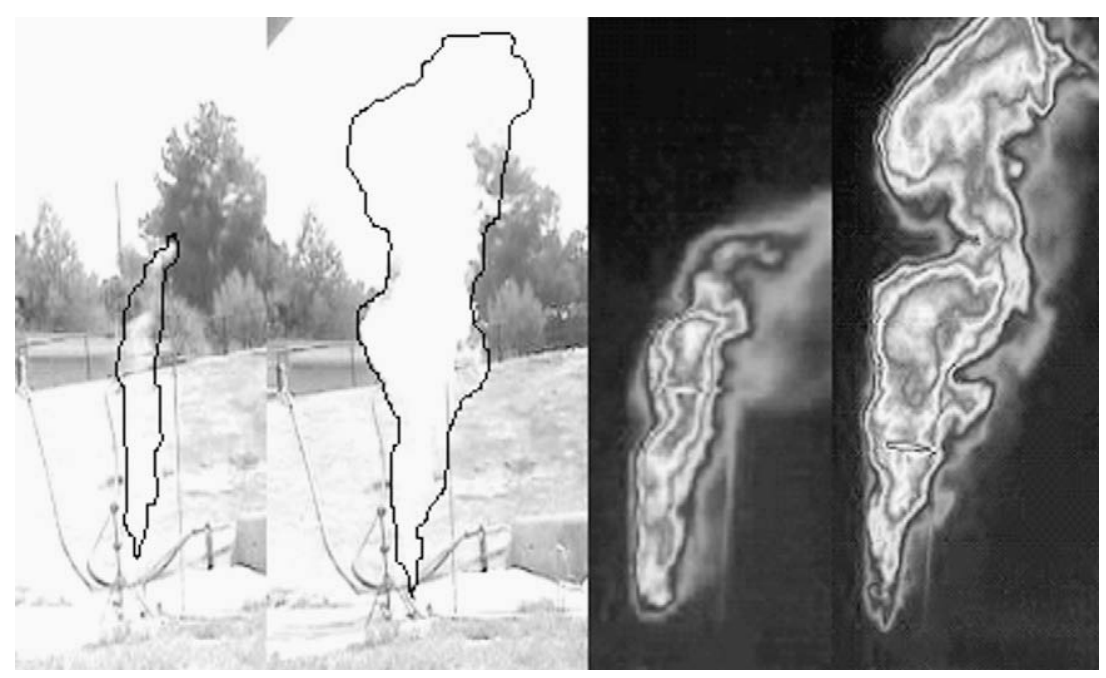

Fig. 2. Flame features as a function of the fuel condition: gas phase and two-phase flow flames. Left: visible image; right: infrared image.

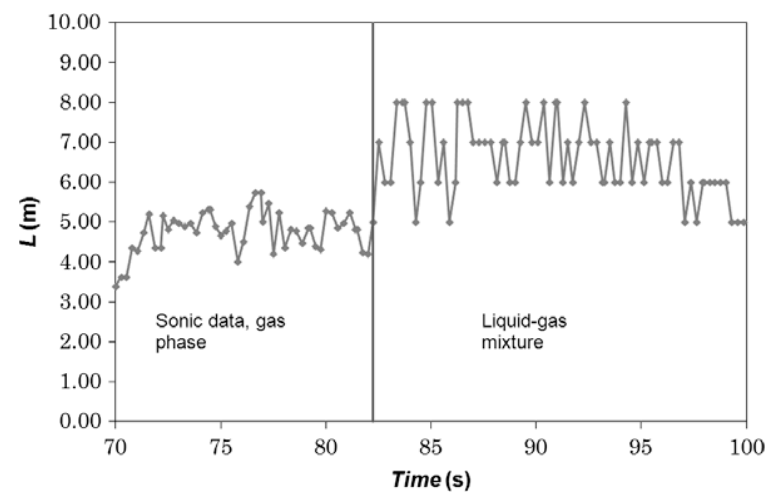

Fig. 3. Variation of flame length when the fuel changes from gas to two-phase flow.

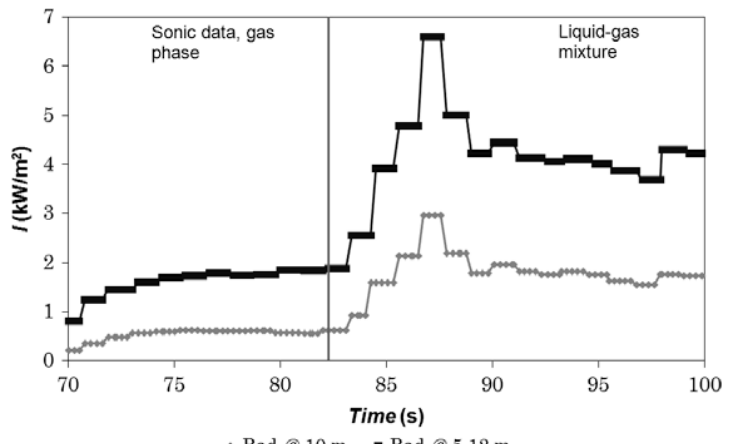

Fig. 4. Variation of the thermal radiation intensity when changing the fuel from gas to two-phase flow.

Eq. (1) it is possible to estimate the surface emissive power $E$ $\left(\mathrm{kW} \mathrm{m}^{-2}\right)$ or average radiant flux emitted from the flame.

In the literature $[3,8]$ the atmospheric transmissivity is often taken as the unity. However, in order to obtain a better estimation of $E$, it should be taken into account that some of the radiant heat is absorbed by the atmosphere; in this study $\tau$ has been estimated $(\tau<1)$ from the atmospheric humidity.

For comparison with other authors it is important to point out that the emissive power $E$ can also be also expressed as:

$E=\varepsilon \sigma T^{4}$

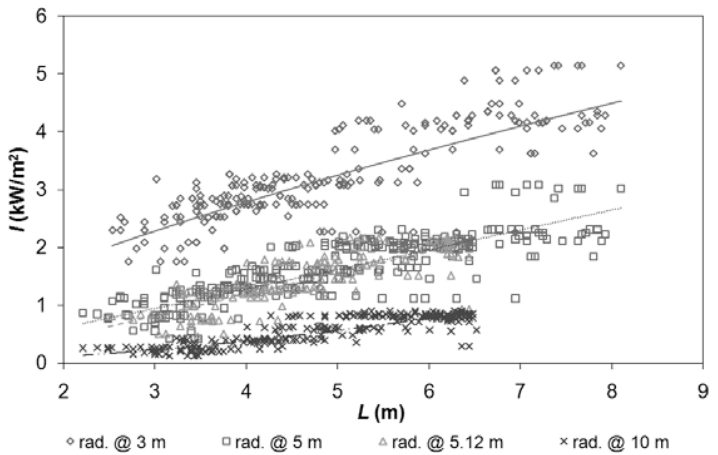

Fig. 5. Thermal radiation intensity as a function of the flame length for different radiometer radial positions.

where $\varepsilon$ is the flame emissivity; $\sigma$ is Stefan-Boltzmann constant and $T$ is the flame temperature.

Thus:

$I=F\left(\varepsilon \sigma T^{4}\right) \tau$

For mass flow rates ranging between $0.09 \mathrm{~kg} / \mathrm{s}$ and $0.43 \mathrm{~kg} / \mathrm{s}$ it can be observed (Fig. 5) that $I$ at a given distance increases with the flame length. Of course, the radiometers located far from the flame measured lower values than those located close to the flame.

In this figure, although the general trend is clear, the data measured by the radiometers show an important scattering. This behaviour had been previously observed by other authors; for example, Sonju et al. [8] registered a variation of $60 \%$ in their results (a higher dispersion than the one obtained here). This scattering can be attributed to the turbulence phenomena as well as to the flame size oscillation. The scattering increases with the distance between the radiometer and the flame; for short distances, the flame oscillation has little influence on the sensor measurements.

The expressions correlating the data of Fig. 5 are shown in Table 1. As can be observed, the agreement with the experimental data is not quite good (low values of $R^{2}$ ) but it increases with the distance from the flame. This scattering must be attributed to the turbulence of the phenomenon and the oscillation of the flame. Although this type of equations are specific just for this situation (fuel, distance), they make easier the calculation of the incident radiant heat without requiring the calculation of the view factor and the knowledge of the emissive power. Thus, they can be interesting for engi- 
Table 1

Empiric expressions describing the variation of the thermal radiation intensity as a function of flame length for several distances.

\begin{tabular}{cll}
\hline$x(\mathrm{~m})$ & Equation & $R^{2}$ \\
\hline 3 & $I=1.07 L^{0.69}$ & 0.57 \\
5 & $I=0.3 L^{1.05}$ & 0.66 \\
10 & $I=0.03 L^{1.75}$ & 0.74 \\
\hline
\end{tabular}

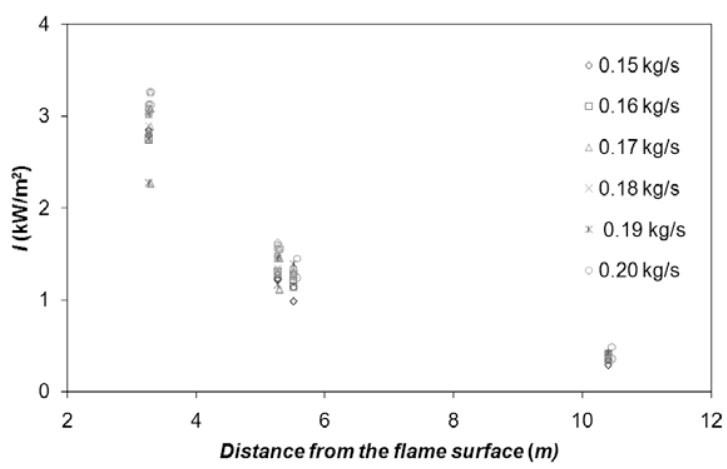

Fig. 6. Variation of thermal radiation intensity with the radial distance from the flame surface.
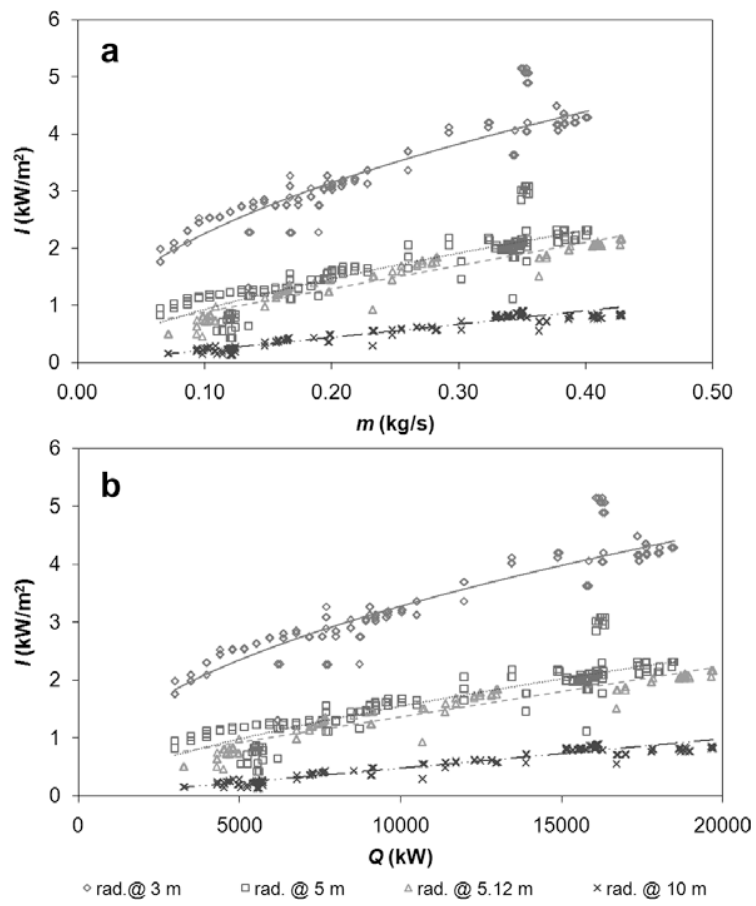

Fig. 7. Thermal radiation intensity as a function of $m$ (a) and $Q(b)$.

neering calculations for specific installations as, for example, LPG storage tanks.

This behaviour can be observed in a clearer way in Fig. 6, where the measurements for some mass flow rates have been plotted: the larger the distance from the flame, the bigger the amount of heat absorbed by the atmosphere. This, together with the variation of the view factor, leads to the decrease of the thermal radiation received by the target as a function of the distance.

If the thermal radiation intensity is plotted versus the mass flow rate $m$, a less scattered plot is obtained (Fig. 7a); it can be observed that the higher the propane mass flow rate, the higher the amount of heat received by the target.

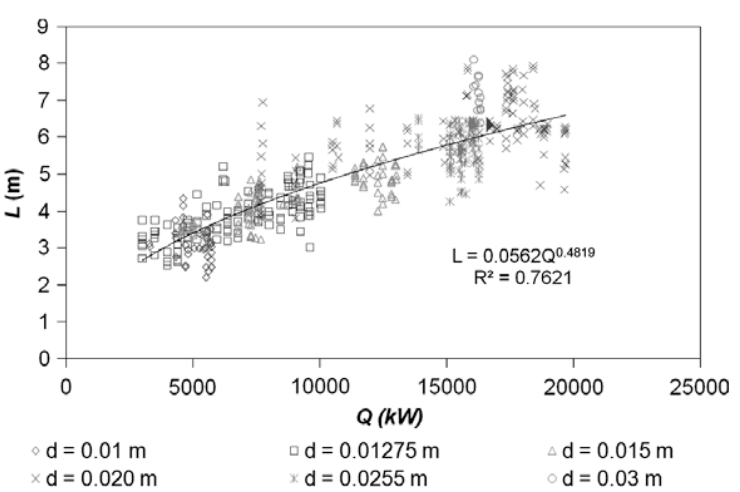

Fig. 8. Variation of visible flame length with the net heat released.

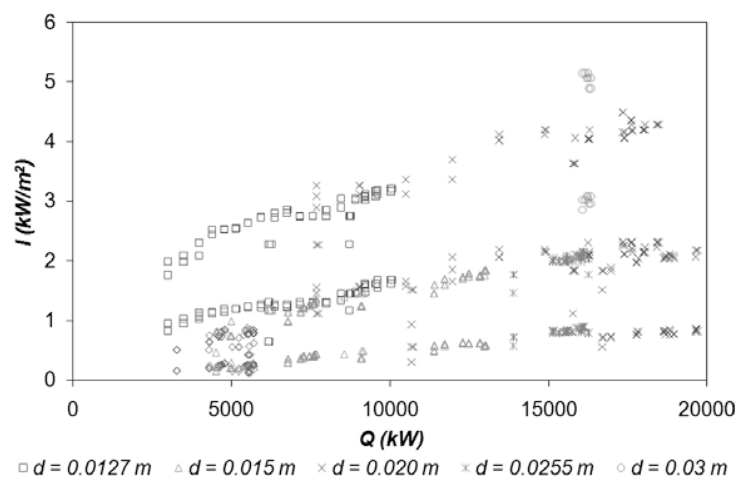

Fig. 9. Incident radiant heat as a function of the net heat released for different exit diameters.

In Fig. 7 the scattering originated by the flame length oscillation has been eliminated. For a specific fuel mass flow rate, the flame can have several lengths. This is another reason to explain why in Fig. 5 the scattering is higher than in Fig. 7, due to the fact that the data corresponding to the same mass flow rate and the same thermal radiation intensity are represented by several points in Fig. 5 while in Fig. 7 they are represented by one single point.

The variation of the flame length depends on the mixture oxygen/fuel: when the optimum ratio is quickly reached, the flame length is shorter than when this ratio takes more time to be achieved. Furthermore, it can be assumed that the energy released by the flame, for different flame lengths, is essentially constant for a given value of the fuel mass flow rate. Moreover, the range of flame lengths reached in each mass flow rate modifies only slightly the view factor, and thus the radiant heat received by a target, from flames with slightly different size, were practically the same.

In the literature, the use of $Q$ (net heat released) instead of $m$ for representing the data is more common, although the plots obtained are equivalent as can be observed in Fig. $7 \mathrm{~b}$.

The relationship between the jet flame length $L$ and the net heat released $Q$ was also analysed. It was observed that generally as $Q$ increases $L$ increases as well (Fig. 8). This behaviour was common for outlet diameters ranging between $12.75 \mathrm{~mm}$ and $30 \mathrm{~mm}$. The maximum heat release rate was about $20 \mathrm{MW}$, while the minimum was $2.5 \mathrm{MW}$ for flames lengths ranging between 3 and $8 \mathrm{~m}$, irrespective of the lift-off height.

This trend can be described by the following expression:

$L=a^{\prime} Q^{b^{\prime}}$

This equation is consistent with other correlations provided by several authors for other fuels [5,6]. In this study, the values obtained for commercial propane are $n_{1}=0.56$ and $n_{2}=0.48$. 


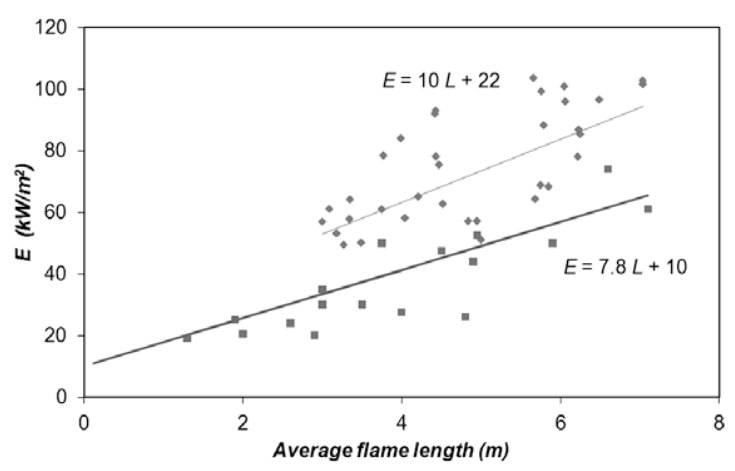

Fig. 10. Variation of emissive power with flame length.

\section{Influence of the exit orifice diameter}

In order to analyze the possible influence of the exit diameter, the thermal radiation intensity has been plotted again as a function of the net heat released for each exit diameter, as can be observed in Fig. 9. It can be noted that the exit diameter has no influence over the incident radiant heat received by a target; the differences found can be attributed to the scattering, common in this type of experiments. This behaviour agrees with the trend found by McCaffrey [2] for methane; as $Q$ increases, the thermal radiation intensity increases as well, with no influence of the exit diameter.

\section{Surface emissive power}

The surface emissive power $E\left(\mathrm{~kW} \mathrm{~m}^{-2}\right)$ was derived from Eq. (1) by computing the view factor $F$ and the atmospheric transmissivity $\tau$ and using the measured values of the thermal radiation intensity. The jet flame was assumed to be a cylinder.

It was found that the surface emissive power increases with the flame length. Fig. 10 shows the variation of average values of $E$ as a function of flame length. Sonju and Hustad data [8] have also been plotted in this figure. These authors worked with turbulent propane flames with exit diameters ranging between 0.002 and $0.08 \mathrm{~m}$ and Mach numbers ranging between 0.3 and 1 (some of their data correspond to subsonic flames). They proposed that the data could be well correlated by a linear equation:

$E=10+7.8 L$

McCaffrey [2] published a similar equation for methane:

$E=26+1.3 L$

For the data analysed in the present study, although the same trend can be observed, there is again some scattering. If the average flame length for each mass flow rate is considered and plotted versus the average emissive power, an equation similar to Eq. (5) is obtained:

$E=22+10 L$

The scattering is significant, but the trend is clearly represented. The difference between Eqs. (5) and (7) is probably due to the differences in the exit velocities, because in this study only sonic flames are considered. Furthermore, Sonju et al. [8] did not include the atmospheric transmissivity in their calculation (which implies a lower value of the emissive power for a specific radiation intensity measured by a radiometer, at a constant distance from the flame).

However, these linear correlations - although proposed by several authors - are indeed not very adequate, because when $L=0$, they still predict a positive value for $E$ (10 for Sonju et al., and 22 for the correlation obtained in this work). This is not at all correct,

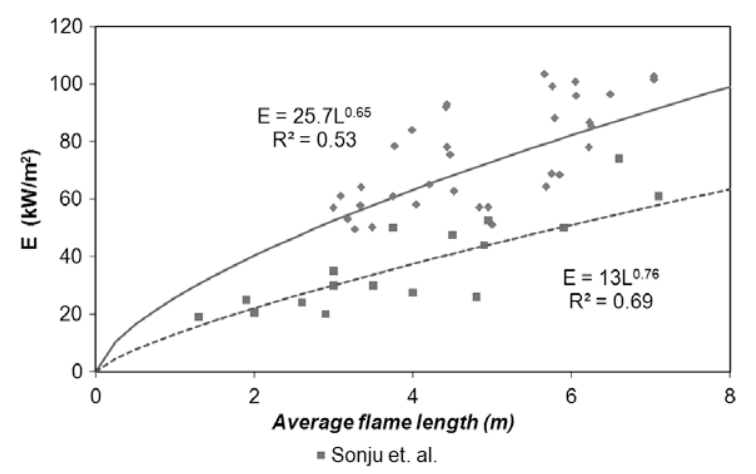

Fig. 11. Average emissive power variation as a function of the average flame length.

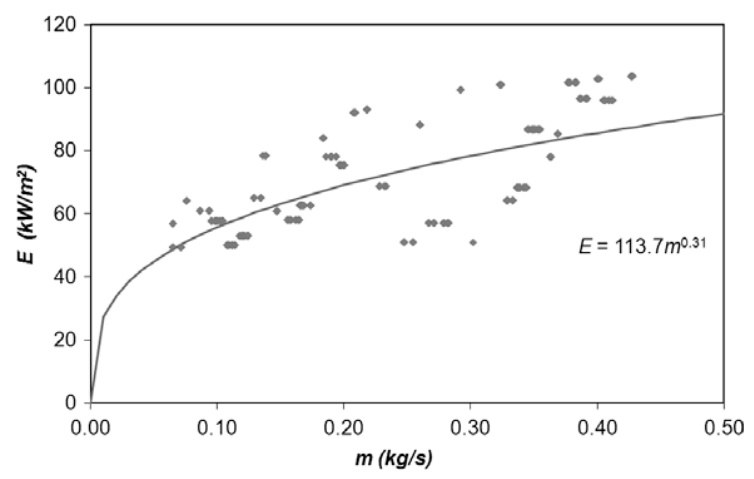

Fig. 12. Variation of average emissive power with mass flow rate.

because when $L=0$ there is no flame and thus, the emissive power should be equal to zero. For this reason, a new general expression is proposed (Fig. 11):

$E=a L^{b}$

Although the scattering is still significant, this trend is more logical as now, when the flame length is equal to zero Eq. (8) predicts $E=0$.

Regarding to the emissive power and the mass flow rate, it can be noted from Fig. 12 that $E$ increases as the mass flow rate is increased. This can be explained in terms of the amount of fuel burned: more fuel is burnt more energy is released. It has to be pointed out that in this figure the experimental values represent again the average emissive power. For the experiments analysed here, the average emissive power ranged between 50 and $100 \mathrm{~kW} \mathrm{~m}^{-2}$; this wide range of values shows again the aforementioned large scattering, which is very difficult to avoid when performing large scale experiments.

\section{Fraction of heat irradiated}

$\eta$ is the fraction of the net heat released that is irradiated from the jet fire. Some time ago, this parameter was considered to be related only to the fuel used, so some correlations were proposed $[11,12]$ giving its value as a function of just the fuel molecular weight. For propane, these correlations considered $\eta=0.33$.

Later on, it was observed that $\eta$ can be affected by the flame conditions: exit velocity of the fuel, wind speed, etc. [2-4,7]. It was noted that $\eta$ drops with the increase of the exit velocity, due to the fact that at higher velocities the flame is blue or there is less yellow luminosity, this indicating a better combustion, or because more heat is lost by convection to the entrained air. Markstein [13] proposed values for $\eta$ ranging between 0.17 and 0.246 , depending on the exit velocity. 


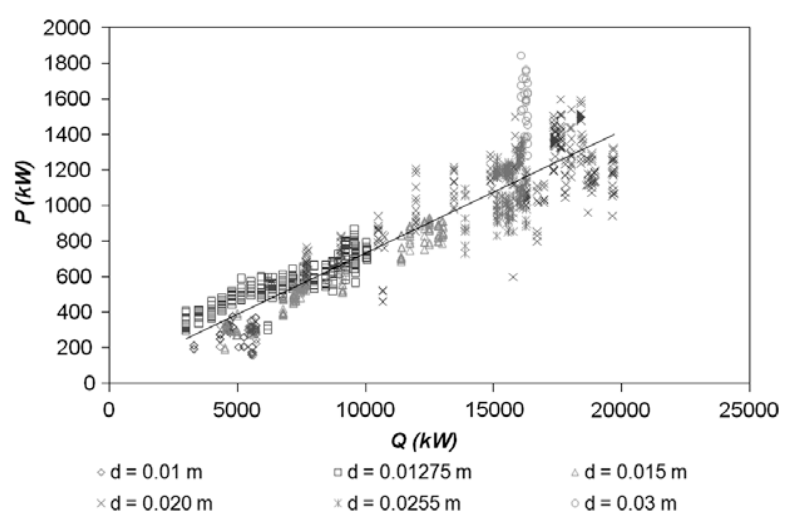

Fig. 13. Variation of total radiative power with the net heat released.
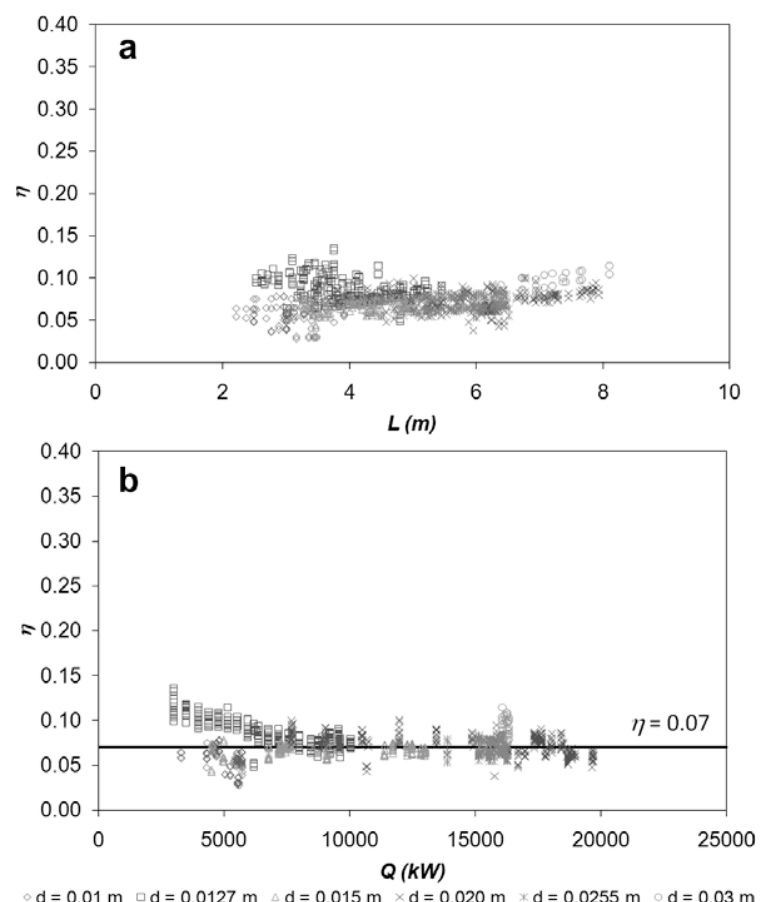

Fig. 14. Variation of $\eta$ with $L$ (a) and $Q$ (b).

In this study the computation of $\eta$ has been based on $E$. Thus, the estimated experimental uncertainty is the same mentioned for the thermal radiation intensity (Section 5 ). To estimate the fraction of the net heat released that has been irradiated it is necessary to estimate the total radiative power $P[3]$ as follows:

$P=E A_{F}$

where $A_{F}$ is the flame cylinder area. The total radiative power $P$ represents all the heat that is irradiated by the entire flame. Thus, the fraction of heat irradiated is:

$\eta=P / Q$

The values of $P$ and $Q$ are plotted in Fig. 13. The slope of the line is the average fraction of heat irradiated, $\eta=0.07$ (standard deviation: 0.01). The low magnitude of this value, as compared with those provided by Kent [11] and Tan [12], can be attributed to the high exit velocity; all the jet fires considered in this study are sonic and, as mentioned before, for high exit velocities the combustion quality increases significantly and the yellow luminosity of the flame decreases. Then the flame is almost transparent and, thus,

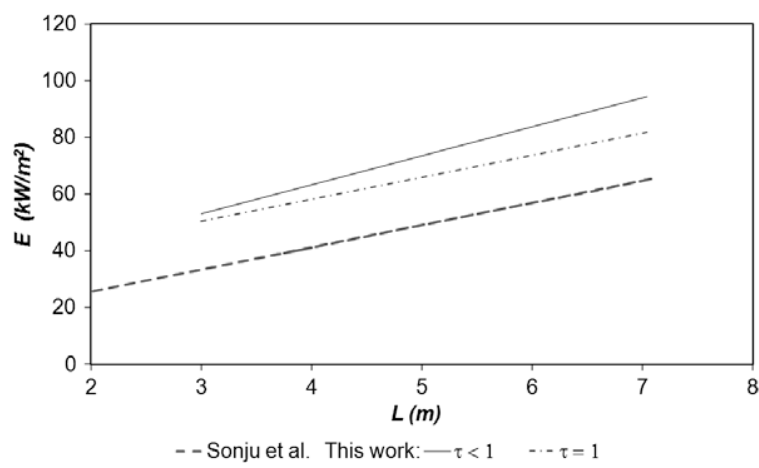

Fig. 15. Effect of assuming $\tau=1$ on emissive power calculations.

the radiant heat decreases. Indeed, according to Brzustowski et al. [7], when the exit flow velocities are high, as in this case, the concentration of condensed species decreases because a higher entrance of oxygen leads to the oxidation of these species, producing again a less luminous flame.

The behaviour of $\eta$ was also analysed as a function of the flame length and the net heat released (Fig. 14). As can be observed, the values for the fraction of heat irradiated ranged between 0.03 and 0.14 , and no effect of the flame length or net heat released was found. The small differences observed can be explained by the scattering of data. Concerning the exit diameter, it does not affect significantly the obtained results, and sometimes the values for different exit diameters overlap. When comparing these data with the Markstein [13] values, the differences can be attributed to the fact that the jets analysed by this author were low velocity buoyancy dominated flames, while the jets analysed here have high velocity and are momentum dominated flames. The Markstein experiments were run inside a building and the flames were shielded by walls, which can affect the ventilation conditions, i.e. the oxygen entrance into the flame; while the experiments shown here were performed in open field. The experimental conditions (exit diameter, ambient temperature, relative humidity, etc.) could also affect the combustion quality. In addition, the common scattering always found in this type of experiments can have some effect as well.

\section{Atmospheric transmissivity}

The effect of assuming the atmospheric transmissivity equal to one can be observed in Fig. 15. For comparison purposes, on that figure the correlation of $E$ as a function of $L$ proposed by Sonju et al. [8], with $\tau=1$, and the proposed in this article (Eq. (7)) with $\tau \neq 1$, have been plotted. Furthermore, the equation equivalent to Eq. (7) but assuming $\tau=1$ has also been plotted just for comparison. As can be observed, when $\tau=1$ is assumed for the data analysed in this paper, the average emissive power resulting from calculations is underestimated, having an error of about $12 \%$; in this case, the resulting equation is closer to the Sonju et al. [8] correlation, being totally parallel to it. The expression obtained with the experimental data analysed in this paper, assuming $\tau=1$ confirms that the differences found between their equation and the one proposed here (with $\tau \neq 1$ ) can be partly attributed to the error introduced by the $\tau=1$ assumption.

The fraction of heat irradiated is also affected by the value attributed to $\tau$ because it is a function of the total radiative power, which depends on $E$. If $\tau=1$ is assumed, then the value found for $\eta$ diminishes from 0.07 to 0.06 .

The error introduced by assuming $\tau=1$ increases with the distance between the flame and the target, as well as with the relative humidity of the atmosphere. 


\section{Conclusions}

The jet fire main features vary according to the fuel conditions (gas or two-phase flow), the flames originated by a gas fuel being quite different from those originated by a gas-liquid mixture: when there are liquid droplets in the fuel, the combustion is less efficient, the flame larger (due to the increase of fuel mass flow rate) and much more luminous and the fraction of heat irradiated is significantly higher. Instead, the jet fires produced by a gas fuel have a better combustion, the flame is much less luminous and the emissive power relatively low. The decay of the thermal radiation intensity as a function of the distance from the flame surface follows an exponential trend. Of course, the radiation intensity increases with the flame size, with the fuel mass flow rate and with the net heat released from the flame. The relationship between the flame length and the net heat released can be described by Eq. (4).

The variation of the surface emissive power - calculated by applying the solid flame model and the measured atmospheric humidity - as a function of the flame length shows a linear trend (Eq. (7)), similar to that obtained by Sonju et al. [8]. A new expression has been proposed (Eq. (8)) which predicts this variation more properly.

Assuming $\tau=1$ introduces an error which leads to lower values of the emissive power. The range of the average emissive power for the experiments analysed here was between 50 and $100 \mathrm{~kW} \mathrm{~m}^{-2}$.

Finally, the fraction of heat irradiated, obtained from the total radiative power and the net heat released from the flame, was found to be 0.07 . This value is significantly lower than those found in the literature. This must be attributed to the fact that most of published data correspond to subsonic jets, sometimes flares, while in this work only sonic jet fires were analysed. At these high exit velocities the combustion is significantly improved and the flame becomes practically blue, the irradiated heat correspondingly decreasing.

\section{Acknowledgments}

The authors are grateful to the Spanish Ministerio de Educación y Ciencia for funding (Projects Nos. CTQ2005-06231 and CTQ200802923/PPQ, and a doctoral Grant for M. G-M).

\section{References}

[1] M. Gómez-Mares, L. Zárate, J. Casal, Jet fires and the domino effect, Fire Saf. J. 43 (2008) 583-588.

[2] B.J. McCaffrey, Momentum diffusion flame characteristics and the effects of water spray, Combust. Sci. Technol. 63 (1989) 315-335.

[3] D.K. Cook, M. Fairwather, J. Hammonds, D.J. Hughes, Size and radiative characteristics of natural gas flares. Part I. Field scale experiments, Chem. Eng. Res. Des. 65 (1987) 310-325.

[4] G.A. Chamberlain, Developments in design methods for predicting thermal radiation from flares, Chem. Eng. Res. Des. 65 (1987).

[5] R. McMurray, Flare radiation estimated, Hydrocarb. Proc. (1982) 175-181.

[6] API521, Guide for Pressure-Relieving and Depressuring Systems, fourth ed., American Petroleum Institute, Washington, DC, 1997.

[7] T.A. Brzustowski, S.R. Gollahalli, M.E. Kaptein, H.F. Sullivan, M.P. Gupta, Radiant heating from flares, ASME Heat Transfer Conf. (1975) 75HT-4.

[8] O.K. Sonju, J. Hustad, An experimental study of turbulent jet diffusion flames, Norw. Marit. Res. 4 (1984) 2-11.

[9] M.A. Muñoz, Estudio de los parámetros que intervienen en la modelización de los efectos de grandes incendios de hidrocarburo: geometría y radiación térmica de la llama. Ph.D. Thesis, Universitat Politècnica de Catalunya, Department of Chemical Engineering, Barcelona, 2005.

[10] W.M. Rohsenow, J.P. Hartnett, Y.I. Cho, Handbook of Heat Transfer, third ed. McGraw Hill, 1998.

[11] G.R. Kent, Practical design of flare stacks, Hydrocarb. Proc. 43 (8) (1964) 121125.

[12] S.H. Tan, Flare system design simplified, Hydrocarb. Proc. 46 (1) (1967) 172176.

[13] G.H. Markstein, Radiative Energy Transfer from Turbulent Diffusion Flames, Technical Report, FMRC Serial Number 22361-2 Factory Mutual Research Corp., 1975. 